\title{
Vibration Energy Harvesting for Disaster Asset Monitoring Using Active RFID Tags
}

\author{
Abhiman Hande, Raj Bridgelall, and Ben Zoghi
}

\begin{abstract}
This paper highlights the importance of energy harvesting in high-value asset monitoring applications involving use of active RFID tags. The paper begins by highlighting advantages of active tags including improved range and read rate in electromagnetically unfriendly environments. Although a battery can substantially improve performance, it limits maintenance-free operational life. Therefore, harvesting energy from sources such as vibration is shown to address this shortcoming but these sources must be adequate, available throughout the life of the application, and highly efficient. Piezoelectric vibration energy harvesting design procedures and components for such systems are identified. This includes three key components namely, the energy harvesting transducer, power management circuit, and energy storage device. Each component of the energy harvesting system is described and important design criteria are highlighted. Finally, the paper concludes by analyzing vibration data from high value assets used during disaster relief, and describing preliminary results of an energy harvesting prototype with details on system form factors, efficiency, and life.
\end{abstract}

Index Terms - Vibration energy harvesting, active RFID, Micro-Wireless, asset monitoring, remote sensors.

\section{INTRODUCTION}

Radio Frequency (RF) sensors and tags find applications in several areas including inventory control, pallet/container tracking, identification (ID) badges and access control, fleet maintenance, equipment/personnel tracking in hospitals, parking lot access and control, car tracking in rental lots, monitoring product health in manufacturing, and many more. Other applications involve monitoring the health of structures such as bridges, roadways, and buildings for basic maintenance and more critical defects such as corrosion and fractures. There is also a need to track and monitor the condition of materiel in the military supply chain. These can include monitoring the condition of subsistence, ordnance, and replacement parts as they are transported by airplanes, ships, trailers, tanks, and other modes of transportation. Other applications combine the data from vehicular sensors, such as

Manuscript received March 15, 2009.

Abhiman Hande is with TexasMicroPower, Inc, 8111 LBJ Freeway, Ste 1250, Dallas, TX, 75251 (Phone: 972-804-3502; e-mail: ahande@texasmicropower.com).

Raj Bridgelall is with Axcess International Inc., 16650 Westgrove Drive, Suite 600, Addison, TX 75001 (Phone: 972-250-5967; e-mail: rbridgelall@axsi.com).

Ben Zoghi is with Texas A\&M University, College Station, TX - 77843 Office: 979-845-4074 (email: zoghi@ tamu.edu). wheel hub-odometers, tire pressure sensors, and asset tags to improve safety, reliability, and reduce fleet maintenance costs.

Another important application involves monitoring and tracking of high-value assets deployed for disaster relief operations such as acts of terrorism [1] and hurricanes. This includes tracking vehicles, heavy duty machinery, and other critical supplies.

Disaster City is a world leader in emergency response training. It is a place unlike any other in the world. The entire 6.2 million dollar, 52-acre training facility has been designed to deliver the full array of skills and techniques needed by today's emergency response professionals. Located adjacent to the world-renown Brayton Fire Training Field, this mini-city has been designed to simulate various levels of disaster and collapse. Filled with real collapsible structures, this state-ofthe-art training center features a wide array of infrastructure. The Office of Urban Search and Rescue is very interested in utilizing these advanced technologies and facilities for personnel and asset tracking for fire fighters, natural disaster events and homeland security. It simulates dozens of scenarios that look towards better emergency response during drastic situations.

Other applications are personnel and mission-critical asset tracking at the Texas A\&M Disaster City site, utilizing active and passive RFID. On a larger scale solution, this system can be used for underground mine safety and communications, subterranean building safety and communications, indoor/Outdoor Personnel tracking, indoor/Outdoor Moveable asset tracking, environmental test and measurement, and continuous data logging, trending and homeland security concerns.

As these types of applications proliferate, it will become necessary to deploy sensor nodes in hard to reach places. Once thousands of low-cost RF sensors are deployed for any given application, replacing batteries will become an impractical task. Therefore, self-sufficient devices that can operate for an indefinite period of time will be required.

Most of these RF devices are traditionally passive without any energy storage device on board. However, as will be seen in the following section, there are applications that require a battery on board for better throughput and performance which consequently results in limited life and the need for replacement. This paper will investigate the potential for vibration energy harvesting (EH) for active RFID tags with a focus on asset monitoring in disaster relief applications. 
Potential vibration EH circuits and their integration with active RFID tags will be identified accordingly.

The paper is organized as follows. In section II, the advantages of using active RFID technology that incorporates an adaptable Micro-Wireless ${ }^{\mathrm{TM}}$ architecture such as the Axcess $\operatorname{Dot}^{\mathrm{TM}}$ is explained. Section III covers available EH sources and highlights feasibility of using vibrations. Section IV describes the relevant EH system components with a focus on using piezoelectric cantilevers as the transducer. In Sections V, vibration data obtained from tools and equipment that could be deployed in disaster relief operations are documented. This data is used to design the vibration transducer. The system design with power management circuits and preliminary results are described in Section VI. Finally, sections VII and VIII include future directions and conclusions respectively.

\section{MiCRO-WIRELESS TECHNOLOGIES}

Homogeneous RFID technologies such as those that operate either in the low-frequency (LF), high-frequency (HF), or ultra-high frequency (UHF) bands are limited in their ability to simultaneously provide basic capabilities often sought for realtime location tracking applications. For example, when it is important to determine through which of several adjacent portals a high value asset has traveled or which of several small adjacent rooms someone has entered, magnetic field activation zones established around strategic control points can deliver the level of accuracy required. Alternatively, when it suffices to know only the approximate area of an item's location in a rather large open area, then a triangulation method using far-field signal propagation measurements is preferable. Henceforth, multi-frequency, heterogeneous technologies that combine communications in both the nearfield and the far-field have emerged to address conflicting requirements such as simultaneous short distance zone disambiguation and long distance communications [2]. The ability to also support an international standard such as EPC C1G2 and ISO18000-6c broadens the product appeal for openloop business logistics and international trade where the product must provide seamless operation within different regulatory domains.

Micro-Wireless $^{\mathrm{TM}}$ is a new category of RFID that has emerged to incorporate a flexible array of RF physical layers such as near-field, far-field, and backscatter communications. The computing architecture of a Micro-Wireless ${ }^{\mathrm{TM}}$ device incorporates a software defined radio (SDR) core to provide the flexibility for adaptively changing the air-interface protocol when the tag or sensor roams from one wireless infrastructure to the next. The $\operatorname{Dot}^{\mathrm{TM}}$ chip from Axcess International is the first Micro-Wireless ${ }^{\mathrm{TM}}$ architecture that has been optimized for operation with intelligent EH supplies. For maximum efficiency, the SDR algorithms will be energy-aware and tightly coupled with the operations of the EH controller to optimize loading conditions as a function of energy availability across application domains.

\section{ENERgY HARVESTING For ACTIVE RFID TAGS}

Active RFID tags have fairly moderate densities and consume power of the order of several $\mathrm{mW}$ while receiving and transmitting data packets but they are designed to draw a few $\mu \mathrm{W}$ in their sleep state. The issue of powering these systems becomes critical when one considers the prohibitive cost of wiring power to them or replacing their batteries. Obviously, such devices have to be small in size so that they can be conveniently placed in remote locations. This places a severe restriction on their life if alkaline or similar batteries are used to power them. To make matters worse, battery technology hasn't sufficiently improved in terms of energy density and size over the last decade, especially for low power mobile applications such as sensor networks. While an effort is being made to improve the energy density of batteries, additional energy resources need to be investigated to increase the life of these devices.

\begin{tabular}{|c|c|c|}
\hline $\begin{array}{l}\text { Energy Scavenging } \\
\text { Source }\end{array}$ & $\begin{array}{c}\text { Power Density } \\
\left(\mu W / \mathrm{cm}^{3}\right)\end{array}$ & Information Source \\
\hline Solar (Outdoors) & $\begin{array}{c}\text { 15,000-Direct Sun } \\
150 \text { - Cloudy Day }\end{array}$ & Commonly Available \\
\hline Solar (Indoors) & 6-Office Desk & Experiments \\
\hline Vibrations & $100-200$ & Roundy et. al. \\
\hline Acoustic Noise & $\begin{array}{l}0.003 @ 75 \mathrm{~dB} \\
0.96 @ 100 \mathrm{~dB}\end{array}$ & Theory \\
\hline Daily Temp. Variation & 10 & Theory \\
\hline Temp. Gradient & $15 @ 10^{\circ}$ Celsius & Stordeur \& Stark 1997 \\
\hline Piezo Shoe Inserts & 330 & Starner 1996 \\
\hline
\end{tabular}

Fig. 1. Power densities of energy harvesting technologies.

There are several sources of energy that can be used to power active RFID tags. Fig. 1 compares the power generation potential of some of the typical EH modalities which include ambient radiation [3], temperature gradients [4], light [5], and vibrations [6-9]. Among these sources of energy, solar EH through photo-voltaic conversion and vibration energy through piezoelectric elements provide relatively higher power densities, which makes them the modalities of choice. Consequently, this paper explores the feasibility of using piezoelectric vibration $\mathrm{EH}$ for powering active RFID and Micro-Wireless ${ }^{\mathrm{TM}}$ tags in vehicle and high-value asset monitoring applications.

\section{ENERGY HARVESTING CIRCUITS AND SYSTEMS}

The choice of system topologies, components, and circuits are described in this section.

\section{A. EH System Components}

A system-level block diagram of an EH RFID tag or wireless sensor operating from a natural source of energy is shown in Fig. 2. Typically, such a device consists of an 8-bit / 16-bit microcontroller with adequate resources to operate its kernels. The microcontroller manages power to the sensors and data acquisition elements, as well as responds to commands (e.g. from the reader or base station). Primary nonrechargeable batteries are used to provide a $3 \mathrm{~V}_{\mathrm{DC}}$ output voltage for the device's microcontroller, sensor board, and transceiver. The device consumes about 10-20 mA during full 
operation and about 2-10 $\mu \mathrm{A}$ during the dormant or sleep mode. Also, these devices are programmed to sleep for most of the time indicating very low duty cycles. Therefore, a continuous EH source providing at least 100-200 $\mu \mathrm{Whr}$ should be sufficient to power these tags. Note that typical excitation levels for various vibration sources are very low (around 0.03 $\left.-0.3 \mathrm{~g}_{\text {peak }}\right)$ at low frequencies of $10-200 \mathrm{~Hz}$ [8]. Therefore, the EH transducer must be designed to meet these specifications.

From Fig. 2, it is clear that three components constitute the formation of an $\mathrm{EH}$ device.

Energy Harvesting Wireless Sensor

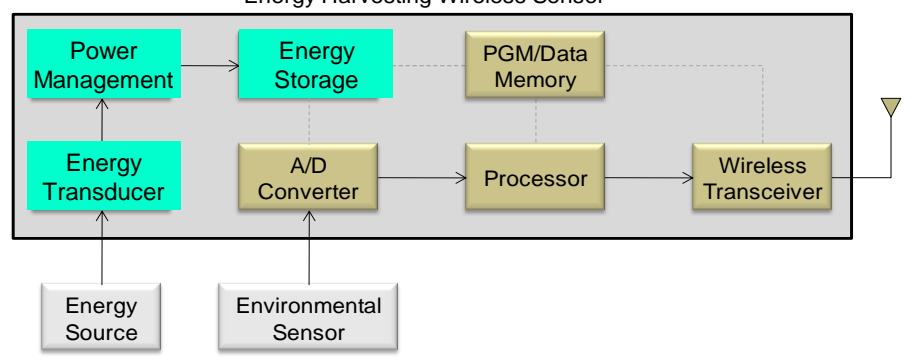

Fig. 2. Block diagram of an energy harvesting sensor

1. EH Transducer (tuned to a specific source frequency band to maximize power harvesting),

2. EH Power Management (AC-DC rectifier and DC-DC converter with adequate impedance matching to enhance energy transfer to storage device), and

3. Energy Storage Component (that stores harvested energy to increase sensor lifetime).

\section{B. Transducer Topology}

Mechanically excited piezoelectric elements possess their own distinct characteristics. A vibrating piezoelectric device differs from a typical electrical power source in that it has a capacitive rather than an inductive source impedance, and may be driven by mechanical vibrations of varying amplitudes [1013]. Piezoelectric devices such as Quickpack QP20W from Mide Technology Corp. are available as a two-layer device that generates an $\mathrm{AC}$ voltage when vibrated in a direction perpendicular to its mid-plane [14]. Therefore, EH circuits that use such devices as sources of energy require a rectifier and
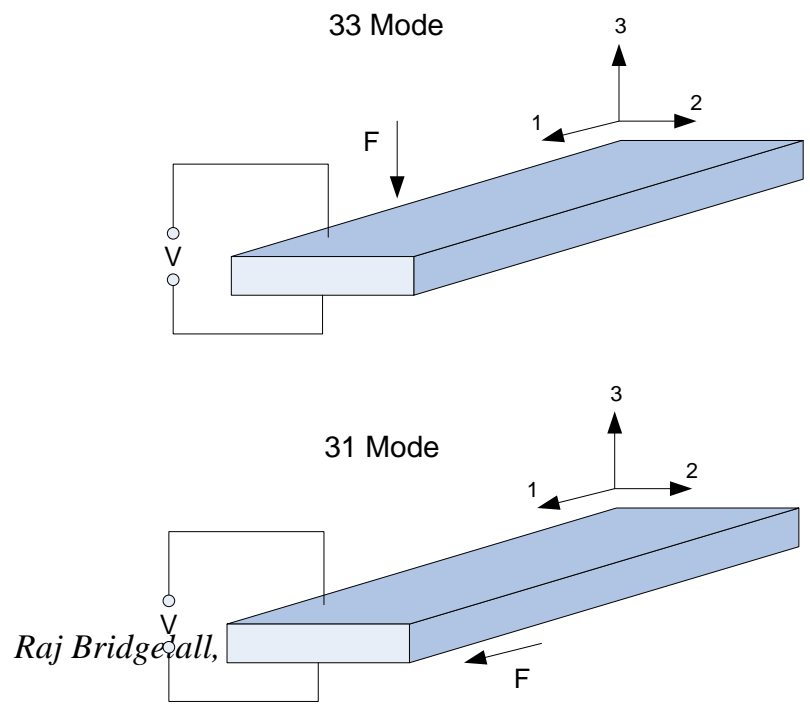

low pass filter to obtain a DC voltage for the embedded system. These components must have low power loss to ensure high system efficiency. The magnitude of current, and hence the optimal rectifier voltage may not be constant as it depends upon the vibration level exciting the piezoelectric element. This creates the need for flexibility in the circuit, i.e., the ability to adjust its average input impedance to achieve maximum power transfer. This means such EH set-ups will need a DC-DC converter between the rectifier and the energy storage mechanism.

Previous studies have characterized the performance of three important types of vibration energy transducers: piezoelectric, electrostatic, and electro-magnetic [8]. These studies indicate that piezoelectric cantilever structures operating in $\mathrm{d}_{31}$ mode are a good choice for powering low power loads such as active RFID tags.

Piezoelectric generators work by straining a piezoelectric material to produce charge separation across the material. For most approaches, the amount of power generated is proportional to the $\mathrm{g}$-force acceleration experienced by an oscillating mass, as well as the oscillating frequency.

Fig. 3 shows the two operating modes $\left(\mathrm{d}_{33}\right.$ and $\left.\mathrm{d}_{31}\right)$ in which the piezoelectric material can be used to generate power. Operation in the $d_{31}$ mode leads to the use of thin bending elements such as bimorphs, in which two separate sheets are bonded together, sometimes with a center shim in between them. $\mathrm{d}_{31}$ systems can produce larger strains with smaller input forces and their resonant frequency is much lower. An immense mass would be required in order to design a piezoelectric converter operating in $\mathrm{d}_{33}$ mode with a resonant frequency below $60 \mathrm{~Hz}$. Therefore, the $\mathrm{d}_{31}$ mode of operation is most suitable for powering active RFID tags.

\section{Power Management Topology}

Fig. 4 shows the basic block diagram of a vibration $\mathrm{EH}$ system using piezoelectric cantilevers as the transducer. The transducer output is an AC voltage that must be first rectified to DC. Several different strategies are available for rectifier design. Due to ease of availability and implementation, low leakage Schottky diodes are feasible for macro level systems. These devices have very low forward voltage drop (about 0.2 $\mathrm{V}_{\mathrm{DC}}$ ) and extremely low leakage currents (of the order of 200 nA). Alternatively, synchronous rectifiers using zero-threshold MOSFETs can be used. Fig. 5 shows one such implementation.

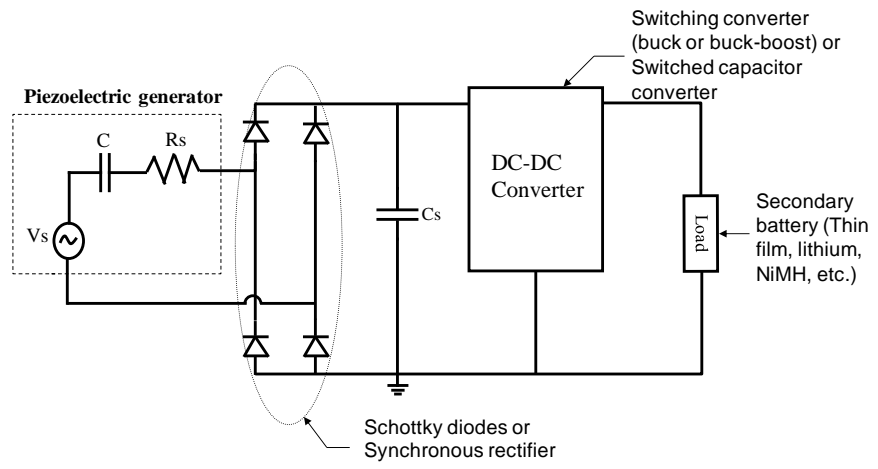

Fig. 4. EH circuit for piezoelectric converters. 
The second stage involves design of a high efficiency DCDC converter to provide regulated DC voltage at the output. The overall efficiency of the system depends upon the efficiency of the rectifier in conjunction with the DC-DC converter. The converter must be designed to match the transducer impedance. This is very important because unlike typical voltage sources, piezoelectric EH transducers are capacitive in nature with high output impedances while typical loads such as batteries have an impedance of the order of few hundred ohms. Without appropriate impedance matching there can be significant loading issues on the voltage source element leading to inefficient power transfer.

There are several DC-DC converter topologies to choose from. Typically, non-isolated switch-mode DC-DC converters seem to be the energy conversion device of choice due to relative ease in matching the transducer impedance [15]. The three most basic converter topologies: buck (step-down), boost (step-up), and buck-boost (step-up/step-down) can all be used to achieve impedance matching.

\section{1) Buck Converter}

It is feasible to use a DC-DC buck converter operating in the discontinuous conduction mode (DCM) along with a pulsecharging circuit to maximize power harvested from piezoelectric elements $[9,16]$. The optimal duty cycle of the converter is dependent on output filter inductance, switching frequency, the piezoelectric element's output capacitance, and the frequency of mechanical excitation.

A typical DC-DC buck converter with a MOSFET input switch is shown in Fig. 6 . The freewheeling diode $\left(D_{1}\right)$ can be replaced with a synchronous rectifier for higher efficiency. It has been shown that maximum energy harvesting efficiency is obtained at the optimal duty cycle (D) given by [16]

$$
D=\sqrt{\frac{4 \omega L C_{p} f_{s}}{\pi}}
$$

where: a) $\omega$ is the resonant frequency of the mechanical host structure,

b) $\mathrm{L}$ is the output filter inductance,

b) $\mathrm{C}_{\mathrm{p}}$ is the piezoelectric element capacitance, and

c) $f_{s}$ is the switching frequency.

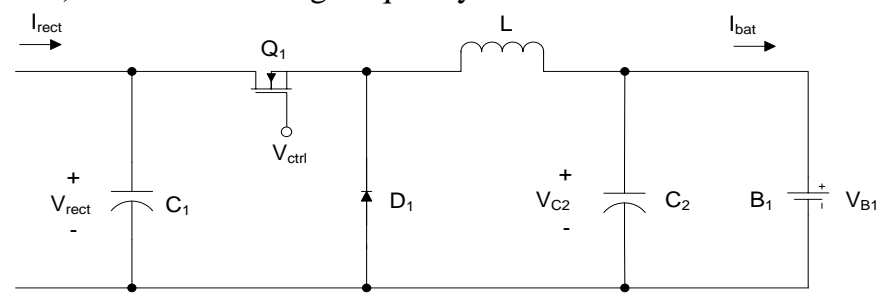

Fig. 6. DC-DC buck converter with battery load.

This equation only holds for large input-to-output converter voltage difference $\left(\mathrm{V}_{\text {rect }}>\mathrm{V}_{\text {bat }}\right)$. High efficiencies $(\approx 65-70$ $\%$ ) have been observed at high levels of input excitation with open circuit rectifier voltage of $>45 \mathrm{~V}_{\mathrm{DC}}$.

\section{2) Buck-Boost Converter}

The buck-boost converter circuit works for input voltages higher and lower than its output voltage. This allows optimization of different EH transducers with energy storage cells of different voltages. Fig. 7 shows the schematic of a typical buck-boost converter. Under DCM the average input resistance $\left(R_{\text {in }}\right)$ is given by $[17,18]$

$$
R_{\text {in }}=\frac{2 L f_{s}}{D^{2}}
$$

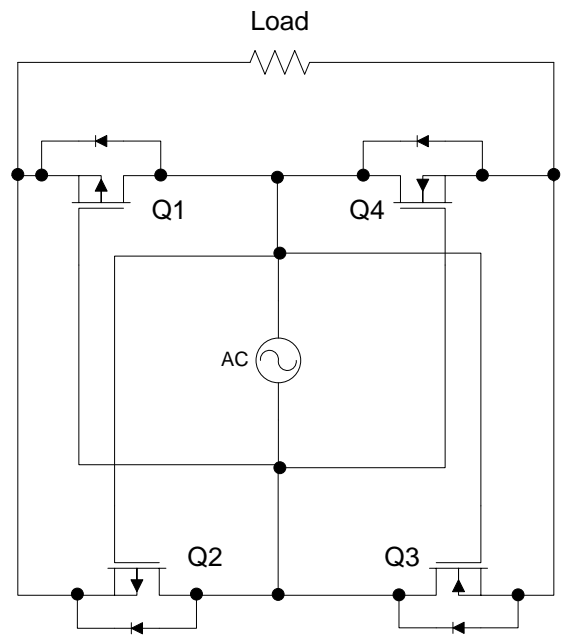

Fig. 5. Synchronous rectifier. $\mathrm{Q}_{1}, \mathrm{Q}_{2}$ are $\mathrm{p}$-channel MOSFETs and $\mathrm{Q}_{3}, \mathrm{Q}_{4}$ are n-channel MOSFETs. Also shown are the respective body diodes.

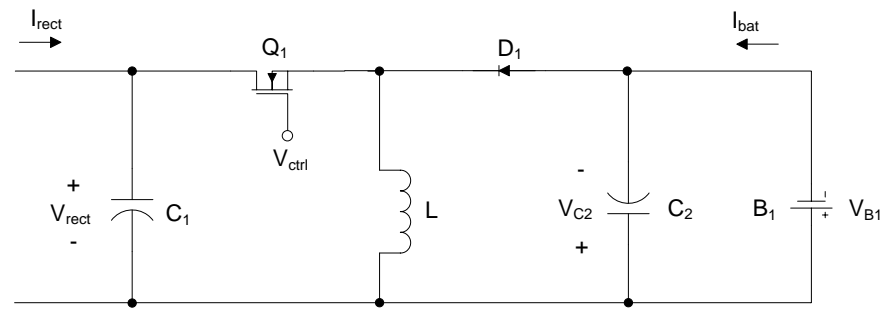

Fig. 7. DC-DC buck-boost converter with battery load.

This indicates that for a constant switching frequency $\left(\mathrm{f}_{\mathrm{s}}\right)$, inductance (L), and duty cycle (D), $\mathrm{R}_{\text {in }}$ is constant and does not depend on the output battery voltage $\left(\mathrm{V}_{\mathrm{B} 1}\right)$ and current ( $\mathrm{I}_{\text {bat }}$ ). Unlike the buck converter, it is not necessary to have a high input-to-output converter voltage differential.

Each of these converters typically supply DC power to an energy storage element at their output. However, a buck-boost converter is observed to be most suitable for low excitation levels, and high efficiency requirements. In addition, active nonlinear synchronized switch harvesting on inductor (SSHI) techniques have been shown to enhance the performance of piezoelectric elements [19].

\section{Energy Storage Device}

The two practical choices available for energy storage are batteries and electrochemical double layer capacitors - also known as ultracapacitors. Batteries are a relatively mature 
technology and have a higher energy density (more capacity for a given volume/weight) than ultracapacitors. Four types of rechargeable batteries are commonly used: nickel cadmium (NiCd), nickel metal hydride (NiMH), lithium-ion (Li-Ion), and sealed lead acid (SLA). Of these, SLA and NiCD batteries are not preferred because the former has a relatively low energy density, and the latter suffers from temporary capacity loss caused by shallow discharge cycles. The choice between $\mathrm{NiMH}$ and Li-Ion batteries involves several tradeoffs. Li-Ion batteries are much more efficient than NiMH batteries, have a longer cycle lifetime, and involve a lower rate of selfdischarge. However, they are more expensive, even after accounting for their increased cycle life [20,21]. An additional consideration is battery aging due to charge-discharge cycles. For example, NiMH batteries (when subjected to repeated $100 \%$ discharge) yield a lifetime of about 500 cycles, at which point the battery will deliver around $80 \%$ of its rated capacity. The residual capacity is significantly higher if the battery is subjected to shallow discharge cycles only. At the rate of one discharge cycle per day, the battery will last for several years before its capacity becomes zero.

Several other battery related factors, which are usually insignificant for conventional mobile devices, also play a role due to the nature of the target system/application. First, the battery non-ideality termed as rate capacity effect is nonexistent since the system's current draw (few tens of $\mathrm{mA}$ ) is an order of magnitude less than the rated current of most present day batteries. Second, the operating temperature of the batteries will vary, leading to changes in battery characteristics. For example, battery self-discharge rate approximately doubles with every $10^{\circ} \mathrm{C}$ increase in ambient temperature [22]. Thus, the choice of battery chemistry for a harvesting system depends upon its power usage, recharging current, and the specific point on the cost-efficiency tradeoff curve that a designer chooses.

Ultracapacitors have a higher power density than batteries and have traditionally been used to handle short duration power surges. Batteries are not as robust as ultracapacitors in terms of depth of discharge, and they tend to lose capacity when exposed to outdoor temperatures. Ultra-capacitors are rated for several thousand charge-discharge cycles as compared to a few hundred cycles for Li-Ion batteries. Battery cycle life is severely reduced when exposed to cold temperatures as well. On the other hand, ultracapacitors possess robust characteristics over a wide temperature range [23]. Recently, such capacitors have been explored for energy storage, since they are more efficient than batteries and offer higher lifetime in terms of charge-discharge cycles. However, they suffer from severe leakage and are expensive.

Therefore, choice of energy storage device depends on a variety of factors including peak power requirements, cycle life, energy storage capacity, cost, and form factor. It is also possible to implement a tiered energy storage mechanism using an ultracapacitor and a battery, to make use of the advantages of both these devices, although there might be some overhead due to the energy storage overhead in the power management module.

\section{VIBRATION SPECTRUM ANALYSIS}

In order to harvest energy from vibrations, the first step involves obtaining the vibration spectrum from the source or structure. It is important to determine the range of frequencies at which maximum force (acceleration) occurs. In this paper, data has been obtained from several vehicles and tools to observe feasibility of designing vibration $\mathrm{EH}$ systems for active RFID tags used for high-value asset monitoring in disaster relief applications. The Texas MicroPower Inc. TMPDL-1 vibration data logger was used to measure the data. This device contains a 3 -axis accelerometer and is well-suited to measure vibration data upto $6 \mathrm{~g}_{\text {peak }}$ with $0.01 \mathrm{~g}_{\text {peak }}$ resolution and sampling rate upto $180 \mathrm{~Hz}$ [24].

Vibration data from several heavy duty vehicles was obtained. EH transducers for active RFID tags will generate optimal power if they are designed to resonate at the source vibration frequency. The vibration frequency spectrum is obtained by running a fast Fourier transform (FFT) on the measured acceleration data. Fig. 8 shows the placement location of the vibration data logger for vehicles such as a hydraulic pump, power saw, BobCat, and a 25 ton crane.

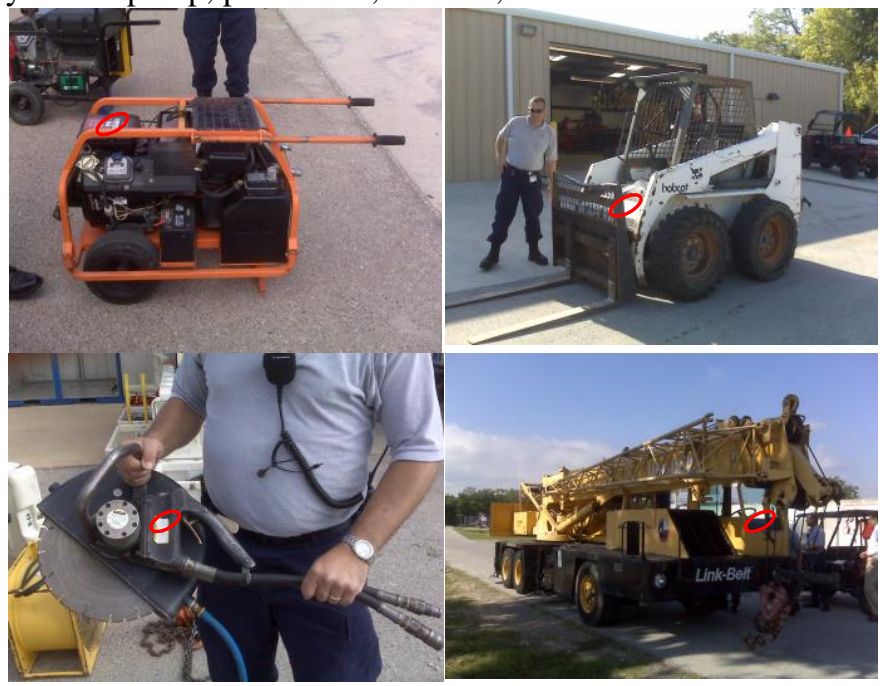

Fig. 8. Vehicles used for vibration data collection and analysis. From counter clockwise: hydraulic pump, power saw, 25 ton crane, and BobCat.

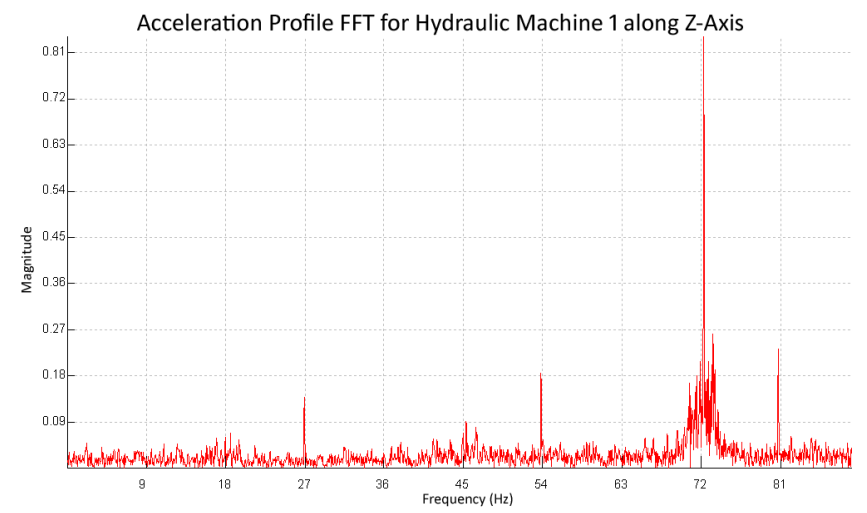

Fig. 9. Frequency spectrum for a hydraulic pump.

Fig. 9 shows the vibration frequency spectrum for a hydraulic pump. The acceleration data is recorded for a few minutes and an FFT algorithm is executed to obtain the 
frequency spectrum. This is used to define the frequency band for transducer design. It is conceivable that multiple bimorphs can be integrated within this frequency spectrum to improve transducer energy output.

The resonant frequency for the hydraulic pump can be seen to be about $72 \mathrm{~Hz}$ with peak acceleration of more than $0.8 \mathrm{~g}$.

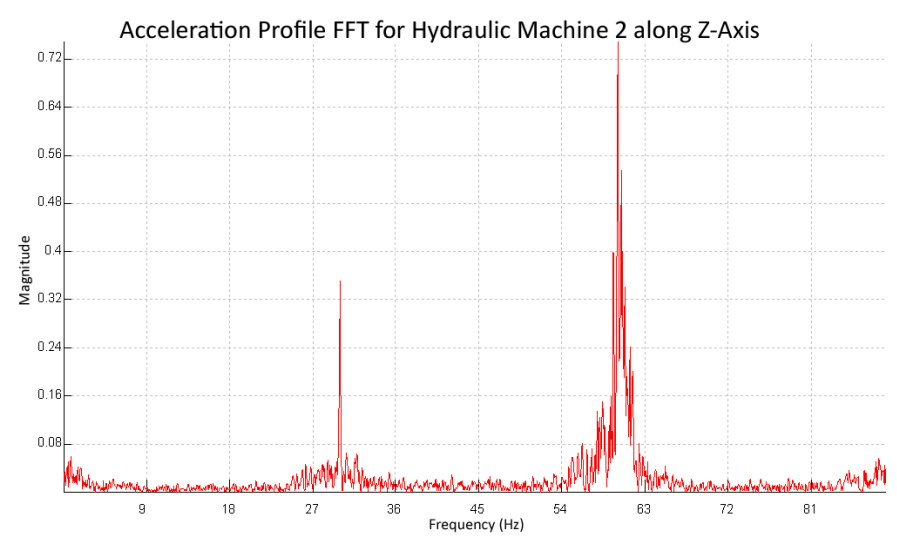

Fig. 10. Frequency spectrum for a power saw.

Similarly, data obtained from the power saw is shown in Fig. 10. It can be observed that in this case, a resonant frequency of $60 \mathrm{~Hz}$ and peak acceleration of more than $0.7 \mathrm{~g}$ were observed.

Relative to machinery, the vibration data obtained from vehicles was much lower. For example, for the BobCat, peak acceleration of about $0.03 \mathrm{~g}$ was observed at about $24 \mathrm{~Hz}$ (refer Fig. 11).

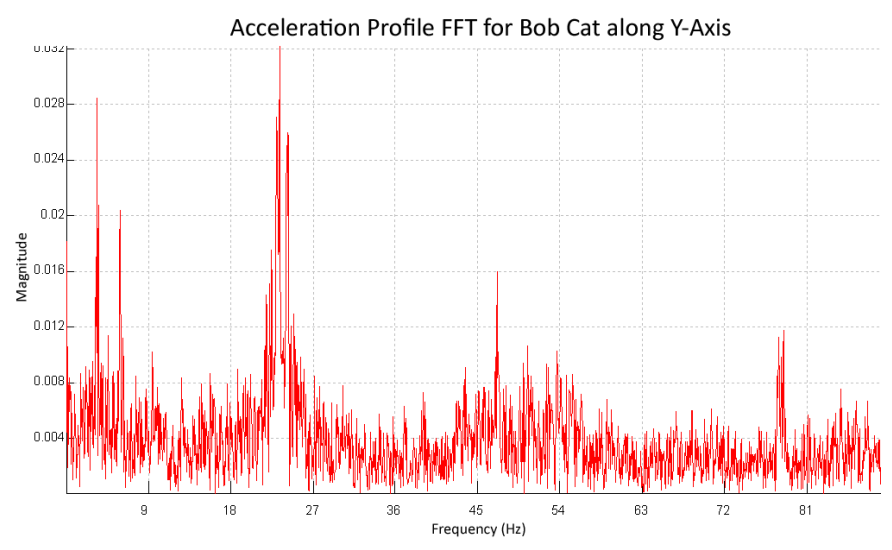

Fig. 11. Frequency spectrum for a BobCat.

\section{EH SYSTEM DESIGN AND PRELIMINARY RESULTS}

An appropriate piezoelectric bimorph can be designed with adequate specifications (e.g. width, length, thickness, tip mass, etc.) that provides the necessary output power at the desired resonance frequency. For the BobCat, the harvester was designed for a resonant frequency $\left(\mathrm{f}_{\mathrm{o}}\right)$ of about $30 \mathrm{~Hz}$. This is a fairly typical $f_{o}$ for vehicles. For tools such as the hydraulic pump and power saw, the harvester must be designed to resonate at their respective $f_{o} s(72$ and $60 \mathrm{~Hz}$ respectively). At these relatively low $f_{o} s$, a large cantilever tip mass is required.
For example, at $30 \mathrm{~Hz}$, a tip mass of about 100 gms was required for the transducer design. A cantilever structure comprising of two Smart Material Macro Fiber Composite (MFC) patches was mounted on a $0.38 \mathrm{~mm}$ Aluminum beam. Due to space restrictions and cost, a slightly higher frequency of about 25-30 Hz was chosen for the transducer design. About 100 gm tip mass was required to obtain $30 \mathrm{~Hz}$ resonant frequency.

It is important to model the piezoelectric transducer at $f_{o}$ using a typical model such as an AC voltage source with series capacitance $(C)$ and resistance $\left(R_{S}\right)$ [25]. This model works well under resonant operating conditions where the transducer output impedance $\left(Z_{0}\right)$ is inversely proportional to $f_{o}$ and given by:

$$
\mathrm{Z}_{\mathrm{o}}=1 /\left(4 \mathrm{f}_{\mathrm{o}} \mathrm{C}\right)
$$

Such a model also provides information on maximum power that can be obtained at matching load impedance. $Z_{0}$ is required for designing a DC-DC converter with average input resistance $\left(R_{\text {in }}\right)$ equal to $Z_{0}$ for maximum power transfer. For example, Fig. 12 shows that maximum power $\left(\mathrm{P}_{\max }\right)$ of 280 $\mu \mathrm{W}$ was obtained at $30 \mathrm{~Hz}$ resonant frequency with a $120 \mathrm{k} \Omega$ load for a PZT-5 based cantilever size of $1 \mathrm{~cm}^{3}$ at $0.08 \mathrm{~g}$ excitation [25]. This would therefore, require the DC-DC converter to be designed for $\mathrm{R}_{\mathrm{in}} \approx 120 \mathrm{k} \Omega$. At higher resonant frequencies, $\mathrm{P}_{\max }$ was slightly lower due to lower transducer output voltages for these frequencies.

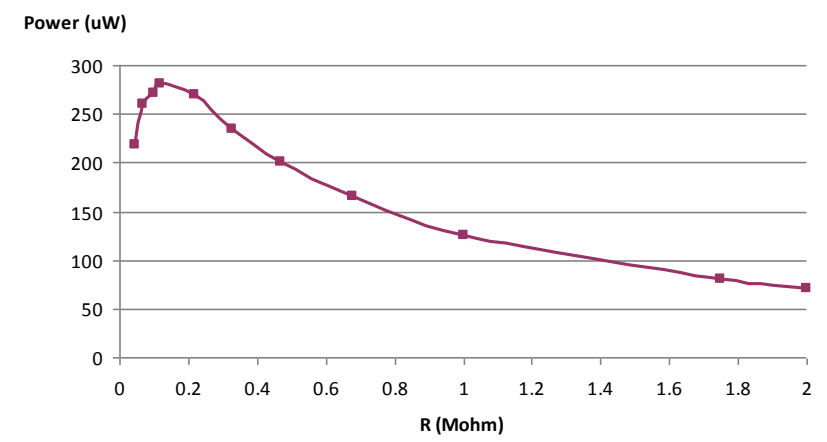

Fig. 12. Simulation results at $45 \mathrm{~Hz} \mathrm{f}_{\mathrm{o}}$ and $0.08 \mathrm{~g}_{\text {peak }}$ accel.

Average power output required to operate the Axcess tags was estimated to be at least $18 \mu \mathrm{W}$. Low leakage Schottky diodes were used for the front-end bridge rectifier design. The design procedure explained in Section IV was used to implement a DC-DC buck-boost converter. In this case, an appropriate value of inductance was chosen to obtain necessary matching impedance of about $100 \mathrm{k} \Omega$. Fig. 13 shows the transducer prototype with power management circuit, lithium polymer secondary battery as the energy storage device, and an Axcess tag circuit board. The overall form factor of the complete prototype is estimated to be $50 \mathrm{x}$ $50 \times 30 \mathrm{~mm}^{3}$ and is expected to be much smaller with a single chip implementation. 


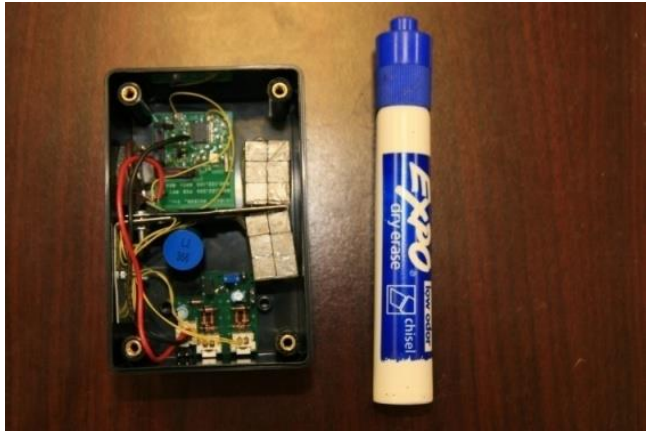

Fig. 13. EH transducer with power management and storage for Axcess tags.

Initial experiments were conducted to verify system operation for energizing the RFID tag. Tests showed that the tag required $40 \mathrm{msec}$ bursts for transmitting its ID to the activator/receiver. Peak current of about $5 \mathrm{~mA}$ was consumed using a $3 \mathrm{~V}_{\mathrm{DC}}$ rechargeable Panasonic VL2020 $20 \mathrm{mAhr}$ battery when active. During off period, current draw was in the tens of $\mu \mathrm{A}$ range with minimum off time at $40 \mathrm{msec}$ and maximum of about $500 \mathrm{msec}$. The HyperTerminal program was set up on a PC to record received data from the activator/receiver. Data was received approximately 5 times per second. Fig. 14 shows the HyperTerminal output, Axcess tags and activator.

The prototype was capable of delivering $>150 \mu \mathrm{W}$ continuous power at low excitation levels of $0.07 \mathrm{~g}_{\text {peak }}$ which is more than sufficient to supply the tag's $18-30 \mu \mathrm{W}$ average power requirements [25]. These tests showed that the harvester prototype was able to sustain charge in battery with continuous vibrations to operate the RFID tag continuously. The experiments used a controlled vibration set-up (e.g. shaker) to conduct experiments based on the vibration data obtained during the field tests (described in Section V).
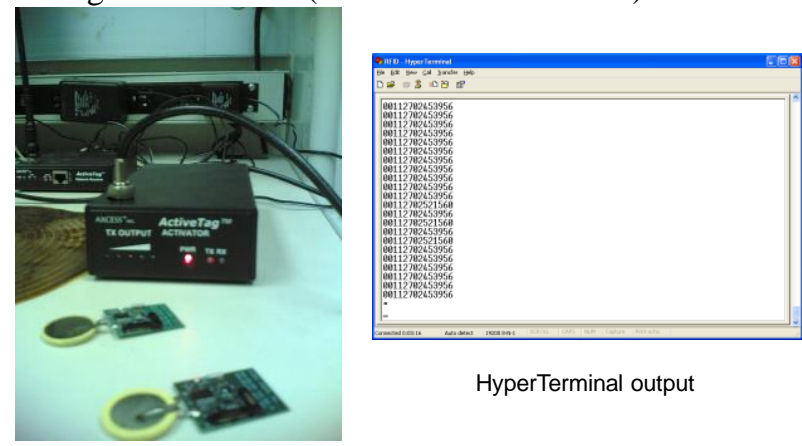

HyperTerminal output

Fig. 14. Axcess tag and activator/reader test results using HyperTerminal program on a PC.

\section{FUTURE DIRECTIONS AND SCOPE}

Future directions suggest integration of $\mathrm{EH}$ transducer, circuits and systems, energy storage devices, power management, and tags onto flexible thin-film substrates to realize smart active labels. Fig. 15 shows the concept for a vibration EH smart label.

In order to harvest energy from vibrations, piezoelectric MEMS based transducers seem to be the obvious choice. Although these systems are not commercially available, researchers in China and MIT have designed such cantilevers. The MIT system consists of a composite micro-cantilever beam with a PZT thin film layer and electrode layer operating in $d_{33}$ mode [26]. A single piezoelectric micro power generator (PMPG) device could deliver about $1 \mu \mathrm{W}$ at $2.36 \mathrm{~V}_{\mathrm{DC}}$ with energy density of $0.74 \mathrm{mWhr} / \mathrm{cm}^{2}$. The second generation PMPG could provide $0.173 \mathrm{~mW}$ at $3 \mathrm{~V}_{\mathrm{DC}}$ with $1 \mathrm{~g}$ excitation at $155.5 \mathrm{~Hz}$ [27]. Investigators from Micro/Nano Fabrication Technology, Shanghai, China have shown that at the resonant frequency of about $608 \mathrm{~Hz}$, a MEMS based generator prototype can output about $0.89 \mathrm{~V}$ AC peak-peak voltage output with output power of $2.16 \mathrm{~mW}$ [28].

Thin film solid state energy storage device research and

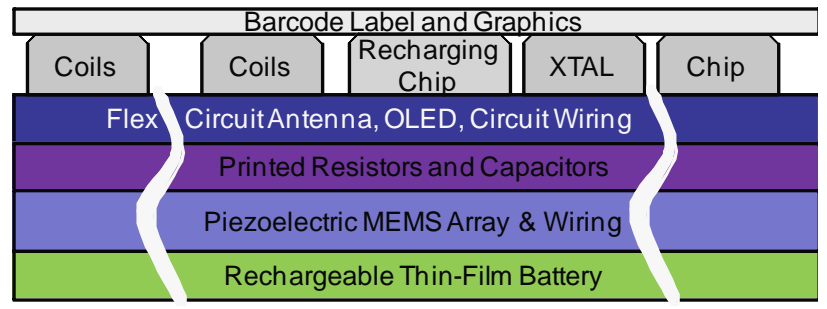

Fig. 15. Smart active sensor.

production (e.g. Cymbet Corp. and Infinite Power Solutions) is also making considerable progress. These devices can operate for thousands of charge-discharge cycles with no memory effect and minimal charge loss over time. These and other related advances indicate good progress towards development of smart active labels. Initially each layer of the tag will have to be individually developed with roll-to-roll manufacturing and then integrated to realize the smart active label. Such devices will reduce the form factor and weight of existing active sensors used in applications such as asset and personnel monitoring, and enable new applications such as smart bandages, labels, stamps, and stickers. Use of multi-source EH with intelligent and adaptive power management techniques can help integration and make these devices practically feasible [29].

\section{CONCLUSIONS}

The design of vibration EH system for active RFID and Micro-Wireless ${ }^{\mathrm{TM}}$ devices used in high-value asset monitoring for disaster relief operations is explored. These low-power wireless sensor applications are very important primarily because of the rapid development of the markets and secondly, due to the limited life of batteries. This, in particular, adds cost and limits deployment of these devices to high-value asset and limited life applications. Although the advantages of these devices are enormous in terms of communication range, throughput, and reliability, the battery cost and its replacement do hamper adoption rates. Harvesting energy from vibrations can extend battery life and at the bare minimum replenish idle energy consumption which is a dominant factor in battery life reduction. Design of new RF sensor fabrication (e.g. smart labels) and device technology (e.g. communication protocols) are steadily decreasing the energy requirements and therefore, smart power management and $\mathrm{EH}$ techniques allow a realistic possibility for perpetual node life. 


\section{REFERENCES}

[1] Axcess International Inc., "AXCESS Awarded \$2 Million Contract for Integrated RFID and Sensor Port Security Solution in Barbados", Press Release, March 2007.

[2] R. Bridgelall, "Introducing a Micro-Wireless ${ }^{\mathrm{TM}}$ Architecture for Business Activity Sensing", IEEE International Conference on RFID, Las Vegas, NV, April 16 - 17, 2008.

[3] E. Yeatman, "Advances in Power Sources for Wireless Sensor Nodes", International Workshop Wearable and Implantable Body Sensor Networks, pp. 20-21, Imperial College, 2004.

[4] J. Stevens, "Optimized Thermal Design of Small $\Delta \mathrm{T}$ Thermoelectric Generators", 34th Intersociety Energy Conversion Engineering Conference, paper 1999-01-2564, Society of Automotive Engineers, 1999.

[5] H. Schmidhuber and C. Hebling, "First Experiences and Measurements with a Solar Powered Personal Digital Assistant (PDA)", 17th European Photovoltaic Solar Energy Conference, pp. 658-662, ETA-Florence and WIP-Munich, 2001.

[6] C. Shearwood and R. Yates, "Development of an Electromagnetic Micro-generator", Electronics Letters, Vol.33, No.22, pp.1883-1884, October 1997.

[7] R. Amirtharajah and A. Chandrakasan, "Self-Powered Signal Processing using Vibration-Based Power Generation", IEEE Journal of Solid-State Circuits, Vol.33, No.5, pp.687-694, April 2004.

[8] S. Roundy, P. Wright, and J. Rabaey, "A Study of Low Level Vibrations as a Power Source for Wireless Sensor Nodes", Computer Communications, Vol. 26, pp. 1131-1144, July 2003.

[9] G. Ottman, H. Hofmann, and G. Lesieutre, "Optimized Piezoelectric Energy Harvesting Circuit using Step-down Converter in Discontinuous Conduction Mode", IEEE Transactions on Power Electronics, Volume 18, Issue 2, pp. 696-703, March 2003.

[10] J. Kymissis, C. Kendall, J. Paradiso, and N. Gerhenfeld, "Parasitic Power Harvesting in Shoes", 2nd International Symposium Wearable Computing Conference, pp. 132-139, Pittsburgh, PA, Oct. 19-20, 1998.

[11] N. Shenck and J. A. Paradiso, "Energy Scavenging with Shoe-mounted Piezoelectrics", IEEE Micro, Vol. 21, pp. 30-42, May-June 2001.

[12] P. Smalser, "Power Transfer of Piezoelectric Generated Energy", U.S.Patent, 5703 474, 1997.

[13] P. Glynne-Jones, S. P. Beeby, and N. M. White, "Towards a Piezoelectric Vibration-powered Microgenerator", IEEE Science Measurement and Technology, Vol. 148, pp. 68-72, March 2001.

[14] "Piezoelectric Actuators and Transducers", Mide Technology Corp., http://www.mide.com/products/qp/qp20w/qp20w.php, 2008.

[15] A. Hande, R. Bridgelall, and D. Bhatia, "Energy Harvesting for Active RF Sensors and ID Tags", Chapter 18, Energy Harvesting Technologies, ISBN: 978-0-387-76463-4, Springer, 2008.
[16] G. Ottman, H. Hofmann, A. Bhatt, and G. Lesieutre, "Adaptive Piezoelectric Energy Harvesting Circuit for Wireless Remote Power Supply", IEEE Transactions on Power Electronics, Volume 17, Issue 5, pp. 669-676, September 2002.

[17] E. Lefeuvre, D. Audigier, C. Richard, and D. Guyomar, "Buck-Boost Converter for Sensorless Power Optimization of Piezoelectric Energy Harvester", IEEE Transactions on Power Electronics, Vol. 22, No. 5, September 2007.

[18] A. Rajasekaran, A. Hande, and D. Bhatia, "Buck-Boost Converter Based Power Conditioning Circuit for Low Excitation Vibrational Energy Harvesting", Third Annual Austin Conference on Integrated Circuits and Systems, Austin, TX, May 2008.

[19] E. Lefeuvre, A. Badel, C. Richard, and D. Guyomar, "Piezoelectric Energy Harvesting Device Optimization by Synchronous Electric Charge Extraction", Journal of Intelligent Material Systems and Structures, Vol. 16, pp. 865-876, October 2005.

[20] D. Berndt, "Maintenance-Free Batteries", $2^{\text {nd }}$ Ed., Research Studies Press Ltd., Taunton, England, 1997.

[21] D. Linden, "Handbook of Batteries and Fuel Cells", New York: McGrawHill, 1984.

[22] V. Raghunathan, A. Kansal, J. Hsu, J. Friedman, and M. Srivastava, "Design Considerations for Solar Energy Harvesting Wireless Embedded Systems", Fourth International Symposium on Information Processing in Sensor Networks, pp.457-462, April 2005.

[23] A. Burke, "Ultracapacitors: Why, How, and Where is the Technology", Journal of Power Sources, Vol.91, pp.37-50, 2000.

[24] "Portable Vibration Data Logger", Texas MicroPower Inc., http://www.texasmicropower.com/products tech/data logging.htm, 2008.

[25] A. Hande and R. Bridgelall, "High Efficiency Vibrational Energy Harvestor for Active RFID Tags", Second Annual nanoPower Forum, Irvine, CA, June 2008.

[26] R. Sood, "Piezoelectric Micro Power Generator: A MEMS-base Energy Scavenger", M.S. Thesis, Massachusetts Institute of Technology, September 2003.

[27] R. Xia, C. Farm, W. Choi, and S. Kim, "Self-Powered Wireless Sensor System using MEMS Piezoelectric Micro Power Generator", IEEE Sensors Conference, October 2006

[28] H. Fang, J. Liu, Z. Xu, L. Dong, L. Wong, D. Chen, B. Cai, and Y. Liu, "Fabrication and Performance of MEMS-based Piezoelectric Power Generator for Vibration Energy Harvesting", Microelectronics Journal, Vol. 37, Issue. 11, pp. 1280 - 1284, 2006.

[29] A. Hande, P. Shah, E. Fernandez, L. Baldenegro, H. Alshareef, and B. Gnade, "Integrated Energy Harvesting with Multisource, Adaptive Interfaces", Fourth Annual Energy Harvesting Workshop, Blacksburg, VA, January 2009 